\title{
ONDAS ULTRASSÔNICAS E PÉROLAS DE VIDRO: UM NOVO MÉTODO DE EXTRAÇÃO DE b-GALAC- TOSIDASE PARA USO EM LABORATÓRIO
}

\author{
Fabiana Oliveira de Medeiros, Fernanda Germano Alves, Cristiane Reinaldo Lisboa, Daniela de Souza Martins, \\ Carlos André Veiga Burkert e Susana Juliano Kalil* \\ Departamento de Química, Fundação Universidade Federal do Rio Grande, Rua Eng. Alfredo Huch, 475, 96201-900 Rio \\ Grande - RS, Brasil
}

Recebido em 22/3/07; aceito em 6/9/07; publicado na web em 26/2/08

\begin{abstract}
ULTRASONIC WAVES AND GLASS PEARLS: A NEW METHOD OF EXTRACTION OF $\beta$-GALACTOSIDASE FOR USE IN LABORATORY. The optimization of a traditional technique of cellular disruption by abrasion was carried out and a process using ultrasonic waves associated with glass pearls to extract $\beta$-galactosidase from Kluyveromyces marxianus proposed. In the first case, the effects of the diameter and weight of the pearls in relation to the volume of cellular suspension and amount of time for cellular disruption were evaluated. The efficiency of the new process of cellular disruption was evaluated by varying the length of time of sonification and comparing with the method of abrasion under the same conditions. The proposed method can be efficiently applied to obtain $\beta$-galactosidase at laboratory scale.
\end{abstract}

Keywords: $\beta$-galactosidase; cellular disruption; sonification.

\section{INTRODUÇÃO}

A $\beta$-galactosidase ( $\beta$-D-galatosídeo galactohidrolase, EC 3.2.1.23) é uma importante enzima utilizada industrialmente na hidrólise de lactose de leite e de soro de queijo. Este dissacarídeo, de baixo poder adoçante, ao ser ingerido por pessoas intolerantes alcança o intestino delgado sem ser afetado e, finalmente, sofre fermentação microbiana no intestino grosso, causando inchaço abdominal, diarréia e outros distúrbios gastrintestinais ${ }^{1,2}$.

A importância da $\beta$-galactosidase vem sendo também ressaltada por sua propriedade de gerar derivados de lactose através de transgalactosilação para formar galactooligossacarídeos (GOS), considerados alimentos funcionais. Por não serem digeridos, os GOS podem alcançar a flora bacteriana no cólon e promover a proliferação intestinal de Bifidobacterium, o que faz deles importantes aditivos em fórmulas infantis e em outros produtos lácteos ${ }^{3,4}$.

A $\beta$-galactosidase é largamente encontrada na natureza, distribuída entre animais, vegetais e microrganismos, sendo que suas características variam de acordo com sua origem. As condições ótimas de temperatura e $\mathrm{pH}$ para sua aplicação diferem de acordo com a fonte, podendo ser isolada de bactérias, leveduras e fungos ${ }^{5}$.

$\mathrm{O}$ uso crescente de processos fermentativos para manufaturar produtos específicos, incluindo proteínas, enzimas ou fármacos, tem gerado uma intensa demanda por sistemas eficientes para recuperação de materiais intracelulares oriundos de microrganismos ${ }^{6}$. Quando a enzima $\beta$-galactosidase é obtida de células de leveduras do gênero Kluyveromyces, ela é intracelular. Assim, para esta recuperação, a célula precisa ser rompida ${ }^{7}$.

A ruptura celular é a primeira etapa no processo de isolamento de materiais intracelulares e constitui uma etapa essencial no processo de "downstream", possuindo considerável influência não somente na quantidade total da proteína de interesse a ser recuperada, mas também na sua atividade biológica, sua associação com outros componentes celulares e a possível presença de degradação proteolítica e contaminantes que podem influenciar nas etapas sub-

*e-mail: dqmsjk@furg.br seqüentes de purificação. O processo de ruptura celular constitui o fator chave na produção e purificação de enzimas intracelulares, o qual tem um importante efeito na recuperação e qualidade do extrato proteico obtido ${ }^{6}$.

Cada microrganismo possui características individuais quanto à localização das enzimas intracelulares que produz, o que significa que uma enzima de interesse pode estar no citoplasma, no periplasma ou, ainda, estar armazenada no interior de alguma organela celular, tal como a mitocôndria. Desse modo, o protocolo de extração pode variar em função da enzima desejada ${ }^{8}$.

Devido ao tamanho maior e à diferença na estrutura da parede celular, a ruptura de leveduras em geral é mais fácil que a ruptura de bactérias. Os componentes básicos da parede celular de leveduras são glucanas, mananas e proteínas. Em geral, métodos mecânicos não são específicos, mas possuem alta eficiência e ampla aplicação em comparação com outros métodos. As características do processo de ruptura podem variar com base na estabilidade mecânica do microrganismo, a qual depende da espécie, idade da cultura, taxa de crescimento específico, temperatura de cultivo e meio de cultura ${ }^{6,9}$.

Diferentes métodos podem ser empregados para extração de proteínas intracelulares, os quais dependem da força física da parede celular dos microrganismos, localização dentro da célula, estabilidade e do uso desejado para o composto de interesse ${ }^{10,11}$. Métodos mecânicos, físicos, químicos, enzimáticos e a combinação destes podem ser aplicados. No entanto, pelo fato da $\beta$-galactosidase ter sua aplicação na modificação de alimentos, permanecendo no produto final, a ruptura das células de Kluyveromyces não deve ser conduzida por métodos químicos, pois implicaria na necessidade de remoção de contaminantes, aumentando os custos de produção. Por outro lado, os métodos mecânicos e físicos de ruptura celular não implicam em riscos de toxicidade, pois não incluem produtos químicos no extrato enzimático.

A tradicional técnica de ruptura celular por abrasão possui alguns inconvenientes para uso em pequena escala, como a manutenção de baixas temperaturas para preservação da atividade biológica da enzima, assim, torna-se importante o estudo e a avaliação de novos processos de extração. 
O objetivo deste estudo foi otimizar a tradicional técnica de abrasão usada para ruptura celular em agitador tipo vórtex e propor um novo processo de ruptura celular, baseado no uso conjugado de ondas ultrassônicas e pérolas de vidro para extração de $\beta$-galactosidase de Kluyveromyces marxianus CCT 7081 para uso em escala de laboratório, comparando os dois processos.

\section{PARTE EXPERIMENTAL}

\section{Microrganismo}

Kluyveromyces marxianus CCT 7081 foi utilizado como fonte da enzima. A cultura foi mantida a $4{ }^{\circ} \mathrm{C}$ em ágar inclinado, extrato de malte e levedura ${ }^{12}$; composto por $\left(\mathrm{g} \mathrm{L}^{-1}\right)$ extrato de levedura $(3,0)$, extrato de malte $(3,0)$, peptona $(5,0)$, glicose $(10,0)$ e ágar $(20,0)$.

\section{Fermentação}

O extrato enzimático foi obtido por fermentação submersa utilizando meio composto por $\left(\mathrm{g} \mathrm{L}^{-1}\right)$ extrato de levedura $(1,0)$, $\left(\mathrm{NH}_{4}\right)_{2} \mathrm{SO}_{4}(1,2), \mathrm{KH}_{2} \mathrm{PO}_{4}(5,0), \mathrm{MgSO}_{4} \cdot 7 \mathrm{H}_{2} \mathrm{O}(0,4)$ e lactose $(10,0)$ com pH ajustado para 5,5 $5^{12}$. A fermentação foi realizada em incubadora rotatória a $180 \mathrm{rpm}, 30^{\circ} \mathrm{C}$ por $48 \mathrm{~h}$, iniciada com uma concentração de células de levedura igual a $1 \times 10^{7}$ células $\mathrm{mL}^{-1}$.

\section{Determinação de biomassa}

A concentração de biomassa foi estimada a partir da absorbância a $620 \mathrm{~nm}$, convertida em massa seca de células usando o fator de conversão obtido da curva padrão de biomassa seca ${ }^{7}$.

\section{Ensaios de ruptura celular}

O caldo fermentado foi centrifugado sob refrigeração, a 6000 rpm por $10 \min (4700 \mathrm{x} \mathrm{g})$. O sobrenadante foi descartado e o decantado ressuspendido com tampão fosfato de sódio $0,1 \mathrm{M} \mathrm{pH} \mathrm{7,3}$ para obter uma suspensão celular com $2,62 \mathrm{mg} \mathrm{mL}^{-1}$, a ser utilizada nos ensaios de ruptura ${ }^{13}$.

A otimização do processo de ruptura em agitador tipo vórtex, foi realizada através de ensaios de ruptura com cargas de pérolas de vidro que variaram de 0,44 a $1,10 \mathrm{~g} \mathrm{~mL}^{-1}$, por um período de 10 min. A melhor carga de pérolas determinada foi usada para estudar o efeito do tamanho da partícula na ruptura das células da levedura. Para isso, foram testadas pérolas de vidro de duas faixas granulométricas com diâmetro entre 0,6-0,85 e 0,95-1,05 mm.

As melhores condições estabelecidas em termos de carga e diâmetro de pérolas foram utilizadas para estudar a influência do tempo de processo na ruptura das células em agitador tipo vórtex e em banho ultrassônico, nos tempos de 10, 20, 30 e 40 min, com intervalos de $2 \mathrm{~min}$ em banho de gelo a cada $5 \mathrm{~min}$ de processo para o agitador tipo vórtex e substituição da água do banho ultrassônico a cada intervalo de 10 min de sonificação.

Em todos os ensaios foi realizada nova centrifugação e o sobrenadante foi analisado quanto a atividade enzimática.

Após a determinação do tempo de ruptura mais eficiente em agitador tipo vórtex e banho ultrassônico, utilizando pérolas de vidro, realizou-se nova fermentação, de modo a utilizar o mesmo caldo para comparar a eficiência de ruptura celular entre os dois processos.

Os ensaios de ruptura celular foram realizados em triplicata, tendo como resposta a atividade enzimática. Os dados foram tratados por análise de variância e teste de diferença de médias (Teste de Tukey) utilizando software Statistica 6.0 (Statsoft, 2001).

\section{Determinação da atividade enzimática}

A atividade enzimática foi determinada usando o método baseado na hidrólise do o-nitrofenil- $\beta$-galactopiranosídeo ${ }^{14}$ (ONPG), realizada a $37{ }^{\circ} \mathrm{C}$ por $15 \mathrm{~min}$. A atividade enzimática foi medida pela leitura em espectrofotômetro a $420 \mathrm{~nm}$. Uma unidade de $\beta$ galactosidase é definida como a quantidade de enzima que libera $1,0 \mu \mathrm{mol}$ de o-nitrofenol por minuto.

\section{RESULTADOS E DISCUSSÃO}

Para todos os ensaios de ruptura celular realizados, nos valores de atividade enzimática média, letras iguais indicam que não há diferença significativa e letras distintas indicam diferença significativa a $95 \%$ de confiança.

A Figura 1 apresenta os resultados de atividade enzimática da ruptura das células de Kluyveromyces marxianus CCT 7081 utilizando diferentes cargas de pérolas de vidro.

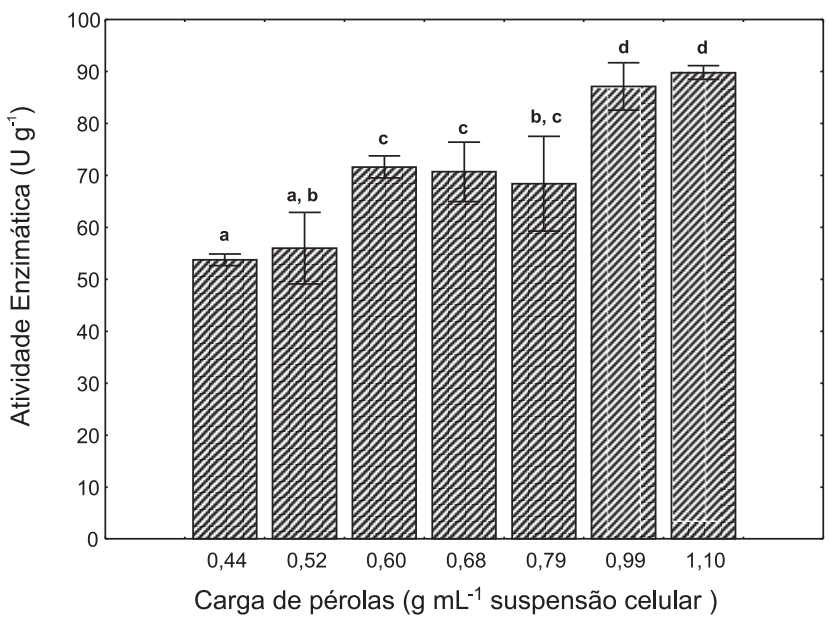

Figura 1. Atividade enzimática média e desvio padrão para o estudo da variação da carga de pérolas de vidro na ruptura de células de Kluyveromyces marxianus CCT 7081 em agitador do tipo vórtex

Como observado na Figura 1, a ruptura das células de levedura foi mais efetiva à medida que a relação carga de pérolas-volume de suspensão celular foi aumentada, evidenciada pelo aumento da atividade enzimática. Através do teste de diferença de médias, foi possível verificar que não existiu diferença significativa entre as cargas 0,99 e $1,10 \mathrm{~g} \mathrm{~mL}^{-1}$ suspensão celular. A relação $1,10 \mathrm{~g} \mathrm{~mL}^{-1}$ suspensão celular foi considerada a melhor, sendo utilizada nas etapas subseqüentes da otimização.

De acordo com Numanoglu e Sungur ${ }^{13}$, cargas de pérolas acima de $0,60 \mathrm{~g} \mathrm{~mL}^{-1}$ suspensão celular, para extrair a enzima, não produzem aumento na atividade enzimática da $\beta$-galactosidase de Kluyveromyces lactis, extraída sob as mesmas condições, o que também se verificou no presente trabalho para os valores de carga de pérolas entre 0,60 e $0,79 \mathrm{~g} \mathrm{~mL}^{-1}$ suspensão celular, que se apresentaram iguais estatisticamente. Entretanto, quando foram utilizadas cargas superiores $\left(0,99\right.$ e $1,10 \mathrm{~g} \mathrm{~mL}^{-1}$ suspensão celular), a atividade cresceu novamente, apresentando valores aproximadamente $20 \%$ maiores aos obtidos naquela faixa.

A Tabela 1 apresenta a atividade enzimática média resultante da ruptura de células de Kluyveromyces marxianus CCT 7081 utilizando pérolas de vidro de diferentes faixas de diâmetro.

Observa-se que os tratamentos foram significativamente diferentes $(\mathrm{p}<0,05)$, sendo as pérolas com diâmetro entre 0,95-1,05 
mm mais eficientes no processo de ruptura das células de Kluyveromyces marxianus CCT 7081, proporcionando uma atividade média $30 \%$ superior.

Tabela 1. Atividade enzimática média e desvio padrão para os ensaios de ruptura celular com diferentes faixas de diâmetros de pérolas em agitador tipo vórtex

Diâmetro das Pérolas (mm) Atividade Enzimática Média (U/g)

\begin{tabular}{ll}
\hline $0,60-0,85$ & $481,10^{\mathrm{a}} \pm 3,78$ \\
$0,95-1,05$ & $625,90^{\mathrm{b}} \pm 3,61$
\end{tabular}

O isolamento da enzima $\beta$-galactosidase de uma suspensão celular de Kluyveromyces marxianus CCT 7081 proporcionou maiores valores médios para atividade enzimática quando a ruptura foi realizada com pérolas na maior faixa de diâmetro estudada. Embora as duas faixas avaliadas sejam maiores que $0,5 \mathrm{~mm}$, como recomendado por Kula e Schütte ${ }^{10}$, existe uma faixa ideal para cada levedura produtora da enzima $\beta$-galactosidase, sendo a faixa de diâmetro 0,951,05 mm ideal para Kluyveromyces marxianus CCT 7081.

Observações experimentais indicam que o tamanho ótimo das pérolas de vidro está relacionado ao tamanho dos microrganismos produtores da enzima de interesse. Para leveduras e bactérias, diâmetros maiores ou menores que $0,5 \mathrm{~mm}$, respectivamente, são considerados ótimos. Pérolas de diâmetro entre 0,10-0,15 mm são indicadas para a ruptura de células bacterianas; enquanto que pérolas entre $0,50-0,75 \mathrm{~mm}$ de diâmetro favorecem a ruptura de leveduras ${ }^{10}$.

A mudança no diâmetro e na carga, das pérolas de vidro foi de suma importância para a eficiência da ruptura. O grau de rompimento celular aumentou com a carga devido ao aumento na interação entre as pérolas e as células contendo a enzima, até certo ponto, a partir do qual o aquecimento do meio pode provocar a desnaturação protéica.

Os resultados para os ensaios do estudo dos tempos de ruptura em agitador tipo vórtex e em banho ultrassônico estão apresentados na Figura 2.

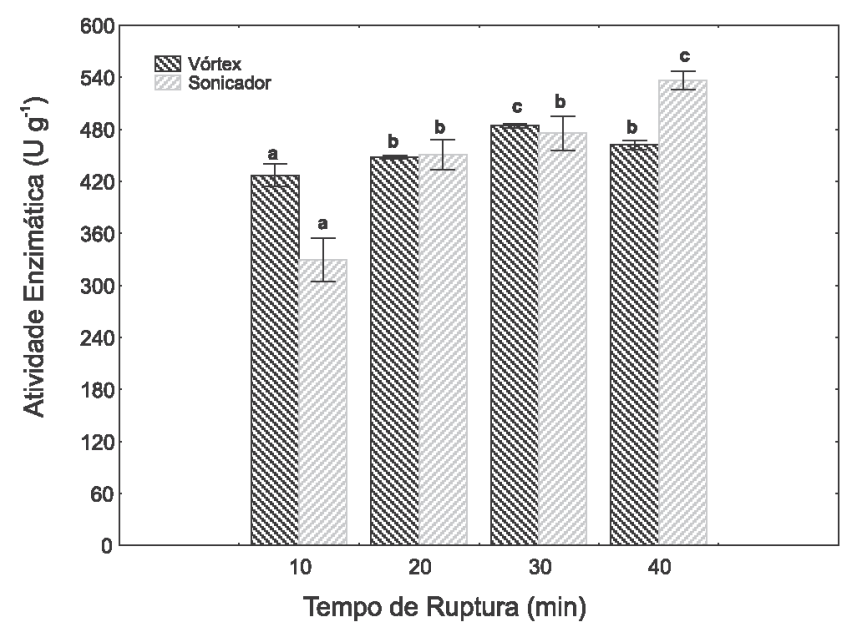

Figura 2. Atividade enzimática média e desvio padrão para o estudo da variação do tempo de ruptura de células de Kluyveromyces marxianus CCT 7081 em agitador do tipo vórtex e em banho ultrassônico

Para a extração usando vórtex, os tempos de 20 e 40 min foram iguais estatisticamente, enquanto os tempos de 10 e 30 min mostraram-se diferentes, sendo este último o que proporcionou o melhor resultado em atividade enzimática. A diminuição na atividade enzimática com o aumento no tempo de ruptura (40 min) ocorreu devido à desnaturação térmica, pois há geração de calor durante o processo, o que também tem sido verificado por diversos autores ${ }^{15,16}$.

Observa-se ainda que tempos de ruptura menores conduzem a uma extração heterogênea, evidenciada pelo maior desvio padrão, enquanto tempos maiores, como 30 min conduzem a maiores valores de atividade enzimática média, pois o rompimento celular é mais homogêneo.

Numanoglu e Sungur ${ }^{13}$ constataram, sob as mesmas condições de trabalho, que tempos acima de 10 min não representavam melhoria significativa na extração desta enzima, o que não aconteceu neste trabalho, pois o aumento no tempo de ruptura favoreceu a extração da enzima. Isto ocorreu até o tempo de $30 \mathrm{~min}$, acima do qual houve perda na atividade. Tempos significativamente superiores ( 2 a 3 vezes) a 10 min proporcionaram resultados mais satisfatórios significativamente, até $10 \%$ superiores.

De acordo com a Figura 2, na extração utilizando ondas ultrassônicas e pérolas de vidro, os tempos de 20 e 30 min foram iguais estatisticamente. O tempo de $40 \mathrm{~min}$ foi diferente dos demais, produzindo uma ruptura mais efetiva. $\mathrm{O}$ aumento do tempo de ruptura proporcionou maiores valores para a atividade enzimática. Pandit e Balasundaram ${ }^{18}$, isolando invertase de Saccharomyces cerevisiae através da mesma técnica, porém sem pérolas de vidro, também verificaram que o aumento no período de tempo de sonificação aumenta a concentração de enzima liberada.

Experimentos anteriores para verificar a eficiência do uso de ondas ultrassônicas para ruptura celular da levedura Kluyveromyces marxianus CCT 7081 sem adição de pérolas de vidro mostraram que não houve liberação da enzima. Entretanto, quando pérolas de vidro foram adicionadas à suspensão celular para ruptura em banho ultrassônico, foi possível extrair a enzima $\beta$-galactosidase. O fenômeno de cavitação associado ao efeito de abrasão gerado pelas pérolas de vidro favoreceram a extração da enzima.

A metodologia de extração baseada no uso do vórtex, embora eficiente em grande escala, onde é possível manter um bom controle da temperatura, torna-se inviável para aplicação em escala laboratorial, pois todos os ciclos de ruptura são realizados manualmente, tornando difícil a manutenção da temperatura adequada para preservação da atividade biológica da enzima. O mesmo não acontece quando se usa banho ultrassônico, como método laboratorial, onde é possível estabelecer um bom controle da temperatura, além de não necessitar de operação manual, como é o caso da extração pelo uso de abrasão em agitador tipo vórtex.

Nos primeiros 10 min de extração, em ambos os processos aplicados, verificaram-se valores elevados para o desvio padrão, devido a que esses tempos não foram suficientes para extrair a enzima, assim, tempos maiores de processo conduziram a uma ruptura mais homogênea.

Vários trabalhos relatam a adoção de pré-tratamentos das células para melhorar a eficiência do processo de sonificação na extração de $\beta$-galactosidase de Kluyveromyces lactis, como a exposição das células da levedura a diferentes valores de $\mathrm{pH}$ e temperatura $^{11,17}$. Desse modo, o processo de sonificação sozinho não foi eficaz para isolamento de $\beta$-galactosidase de Kluyveromyces marxianus CCT 7081, desde que a extração só ocorreu pela adição das pérolas de vidro. Porém, esse processo é bem mais simples que um prétratamento realizado na biomassa.

O tempo de extração é uma variável importante a ser estudada para evitar a desnaturação da proteína alvo. A extração da enzima pela ruptura das células de Kluyveromyces marxianus CCT 7081 em agitador tipo vórtex foi mais susceptível à desnaturação térmica, em função da geração de calor e da dificuldade de controle de temperatura, em escala de bancada. 
No caso da sonificação também existe perda da atividade dependendo da enzima quando a suspensão celular é submetida a muitos ciclos consecutivos ${ }^{15,16}$, o que não ocorreu com a enzima $\beta$ galactosidase, pois o rompimento das células foi realizado submetendo-se a suspensão celular a ciclos de 10 min, com substituição da água do banho a cada intervalo de processo, de modo que a temperatura se manteve em torno de $4{ }^{\circ} \mathrm{C}$.

Os tempos de $30 \mathrm{~min}$ em agitador tipo vórtex e $40 \mathrm{~min}$ em banho ultrassônico foram testados sobre uma mesma suspensão celular, proveniente da mesma fermentação para comparar a eficiência dos dois processos de ruptura na obtenção da enzima $\beta$-galactosidase. Os resultados estão dispostos na Tabela 2.

Tabela 2. Resultados de atividade enzimática para os ensaios de comparação entre os processos de ruptura testados, utilizando o melhor tempo de ruptura

\begin{tabular}{|c|c|c|}
\hline $\begin{array}{l}\text { Métodos de } \\
\text { Ruptura }\end{array}$ & $\begin{array}{c}\text { Tempo de } \\
\text { Ruptura (min) }\end{array}$ & $\begin{array}{c}\text { Atividade } \\
\text { Enzimática }(\mathrm{U} / \mathrm{g})\end{array}$ \\
\hline Agitador do tipo vórtex & 30 & $597,04^{\mathrm{a}} \pm 9,46$ \\
\hline Banho ultrassônico & 40 & $550,39^{\mathrm{a}} \pm 35,02$ \\
\hline
\end{tabular}

Geralmente, em estudos comparativos verifica-se que um ou outro processo é mais eficiente no isolamento de uma proteína específica, tal como procedimentos enzimáticos, aplicação de solventes, sonificação e agitador tipo vórtex ${ }^{6,15}$. No caso da enzima $\beta$-galactosidase os resultados mostraram que ambos os processos avaliados são adequados para extrair a enzima, pois não existe diferença significativa entre os processos de ruptura celular a $95 \%$ de confiança (Tabela 2).

A sonificação também se mostrou efetiva na obtenção de extrato enzimático bruto de $\beta$-galactosidase, quando comparada a métodos que utilizam enzimas ou aplicação de solventes, proporcionando valores superiores em termos de atividade enzimática e proteína recuperada $^{6}$. O novo método de ruptura celular utilizando ondas ultrassônicas e pérolas de vidro foi eficiente para extração de $\beta$ galactosidase, demonstrando ser um método inovador e passível de aplicação em escala laboratorial, seja para fins analíticos, como no acompanhamento da produção de enzima durante uma fermentação, ou mesmo para estudos de purificação, onde é necessário o rompimento da célula para obtenção do extrato enzimático bruto a ser purificado.

\section{CONCLUSÕES}

A utilização de uma carga de $1,10 \mathrm{~g}$ de pérolas de vidro por $\mathrm{mL}$ de suspensão celular, com diâmetro entre 0,95-1,05 mm proporcionou as melhores condições de extração por abrasão em agitador tipo vórtex, por um período de $30 \mathrm{~min}$, para isolamento da enzima $\beta$-galactosidase de Kluyveromyces marxianus CCT 7081.

$\mathrm{O}$ método de ruptura celular proposto, de ondas ultrassônicas associado a pérolas de vidro, por um período de $40 \mathrm{~min}$, pode ser aplicado eficientemente para extração de $\beta$-galactosidase de Kluyveromyces marxianus CCT 7081 em laboratório, podendo ser utilizado com vantagens em substituição ao tradicional método de ruptura por abrasão.

\section{AGRADECIMENTOS}

O presente trabalho foi realizado com o apoio da Coordenação de Aperfeiçoamento de Pessoal de Nível Superior (CAPES) - Brasil.

\section{REFERENCIAS}

1. Gékas, V.; López-Leiva, L.; Process Biochem. 1985, 20, 2.

2. Murad, H. A.; Milk Science International 1998, 53, 273.

3. Yang, S. T.; Silva, E. M.; J. Dairy Sci 1995, 11, 2541.

4. Rubio-Texeira, M.; Biotechnology Advances 2006, 24, 212.

5. Ladero, M.; Santos, A.; García - Ocha, F.; Enzyme Microb. Technol. 2000, $27,583$.

6. Becerra, M.; Siso, M. I. G.; Cerdán, M. E.; Belmonte, E. R.; Food Technology Biotechnology 2001, 39, 135.

7. Rech, R.; Cassini, C. F.; Secchi, A.; Ayub, M.; J. Ind. Microbiol. Biotechnol. 1999, $23,91$.

8. Asenjo, J. A.; Andrews, B. A.; Huang, R. B.; Biotechnol. Bioeng. 1991, $38,977$.

9. Geciova, J.; Dean, B.; Jelen, P.; International Dairy Journal 2002, 12, 541.

10. Kula, M. R.; Schütte H.; Biotechnol. Prog. 1987, 3, 31.

11. Pandit, A. B.; Harrison, S.; Farkade, V. D.; Biochemical Engineering Journal 2005, 23, 247.

12. Pinheiro, R.; Belo, I.; Mota, M.; Letters in Applied Microbiology 2003, 37 , 438 .

13. Numanoglu, Y.; Sungur, S.; Process Biochem. 2004, 39, 703.

14. Committee on Codex Specifications; Food Chemical Codex, $3^{\text {rd }}$ ed., Washington, 1981.

15. Persike, D. S.; Bonfim, T. M.; Santos, M. H. R.; Lyng, S. M. O.; Chiarello, M. D.; Fontana, J. D.; Bioresour. Technol. 2002, 82, 79 .

16. Tan, W. S.; Kamaruddin, S.; Ling, T. C.; Chew, T. K.; Woi Ho, C.; Process Biochem. 2006, 41, 1829.

17. Pandit, A. B.; Harrison, S. T. L.; Farkade, V. D.; Biochemical Engineering Journal 2006, 31, 25.

18. Pandit, A. B.; Balasundaram, B.; Biochemical Engineering Journal 2001, $8,251$. 